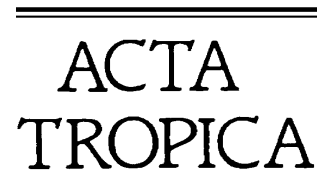

Acta Tropica 84 (2002) 9-17

www.parasitology-online.com

\title{
The dog as model for chemotherapy of the Chagas' disease
}

\author{
Paulo Marcos da Matta Guedes a, Vanja Maria Veloso a, Washington \\ Luiz Tafuri ${ }^{\mathrm{a}}$, Lúcia Maria da Cunha Galvão ${ }^{\mathrm{b}}$, Cláudia Martins Carneiro ${ }^{\mathrm{c}}$, \\ Marta de Lana ${ }^{\mathrm{c}}$, Egler Chiari ${ }^{\mathrm{b}}$, Killarney Ataide Soares ${ }^{\mathrm{a}}$, Maria \\ Terezinha Bahia ${ }^{a, *}$ \\ ${ }^{a}$ Departamento de Ciências Biológicas, Instituto de Ciências Exatas e Biológicas, Universidade Federal de Ouro Preto, UFOP, Morro do \\ Cruzeiro, CEP 35400-000, Ouro Preto, MG, Brazil \\ ${ }^{\mathrm{b}}$ Departamento de Parasitologia, Universidade Federal de Minas Gerais, Belo Horizonte, MG, Brazil \\ ${ }^{\mathrm{c}}$ Departamento de Análises Clínicas, Universidade Federal de Ouro Preto, Ouro Preto, MG, Brazil
}

Received 1 October 2001; received in revised form 10 March 2002; accepted 14 May 2002

\begin{abstract}
In the present study, we investigated the role of dogs as experimental models for acute and chronic phases of Chagas' disease, before and after therapeutic treatments. Dogs were infected with Trypanosoma cruzi strains of different susceptibilities to benznidazole (Bz) and treated with the same therapeutic scheme as used for human chagasic. The treatment with $\mathrm{Bz}$ was able to prevent death and induced parasitological cure in $62.5 \%$ (acute phase) and $38.7 \%$ (chronic recent phase) of the tested animals. These results were similar to those reported in clinical trials for treated human patients (cured and uncured) in both phases of the disease. We also showed that parasitologic and serologic tests for monitoring the cure were similar to those obtained for human trials. In addition, Polymerase chain reaction showed the highest sensitivity when compared with hemoculture as an indicator of parasite clearance. In conclusion, the proposed experimental model should be relevant for chemotherapy studies for the control of Chagas' disease. (C) 2002 Elsevier Science B.V. All rights reserved.
\end{abstract}

Keywords: Canine experimental model; Chagas' disease; Trypanosoma cruzi; Chemotherapy

\section{Introduction}

Chagas' disease is endemic in South American countries, where it is estimated 16-18 million

\footnotetext{
* Corresponding author. Tel.: +55-31-3559-1690

E-mail address: mtbahia@nupeb.ufop.br (M.T. Bahia).
}

persons are affected and 50000 deaths occur annually (WHO, 1993). Although great progress has been made, recently, in the control of the vector and in the transfusional transmission of the disease, the specific treatment of infected individuals remains unsolved.

Drugs such as nitrofurans and nitroimidazoles have been used with variable degree of therapeutic 
success in the acute phase of the disease, and in children in the chronic phase (Shikanai-Yasuda et al., 1990; Andrade et al., 1996; Sosa Estani et al., 1998). Unfortunately, there are no drugs that are highly successful at treating in chronic phases of the disease (Ferreira, 1990). The fact of the matter is the eradication of Trypanosoma cruzi in chagasic patients is of primary importance to prevent the development of the disease and avert its irreversible long-term consequences (Viotti et al., 1994; Andrade et al., 1991).

The evaluation of therapeutic effectiveness of chronic chagasic patients is very difficult due to slow development of the disease, which requires long patient follow-up periods. Moreover, available parasitological methods present low sensitivity, and anti- $T$. cruzi antibodies persist for many years post-treatment in a large percentage of the patients (Galvão et al., 1993). Lytic antibodies are detected by the complement mediated lysis test, which is used to evaluate treatment efficacy (Krettli et al., 1984; Galvão et al., 1993).

The establishment of experimental models that reflect the human disease and studies for specific treatment of Chagas' disease are necessary. Experimentally infected dogs develop acute and chronic phases of chagasic infection that are comparable to clinical signs of the human disease (Andrade and Andrade, 1980; Andrade, 1984; Lana et al., 1992).

In this report, a specific treatment was evaluated in a canine experimental model system for both, the acute (acute model) and chronic (chronic model) phases of Chagas' disease. For the acute model, $50 \%$ of the animals were infected with $T$. cruzi sensitive to benznidazole (Bz), and 50\% with partially resistant and resistant strains. This model takes into consideration the population proportions of $\mathrm{Bz}$ sensitive $(58.6 \%)$, partially resistant and resistant strains $(42.3 \%)$ and the cure index of $60-70 \%$ in the acute phase of Chagas' disease as reported by different researchers (Andrade et al., 1985, 1992; Filardi and Brener, 1987; Galvão et al., 1993; Toledo et al., 1997). For the chronic model, all of the dogs were infected with $T$. cruzi strain Berenice-78, since it is still not clear the importance of the parasites population characteristics on the cure index of this phase.

\section{Materials and methods}

\subsection{Trypanosoma cruzi strains}

T. cruzi strains used in this study were: Colombian, T. cruzi I (Federici et al., 1964), a resistant strain to Bz (Veloso et al., 2001)Y, T. cruzi (Silva and Nussenzweig, 1953), a partially resistant strain to Bz (Filardi and Brener, 1987), and Berenice-78, T. cruzi II (Lana and Chiari, 1986), which is susceptible to Bz (Veloso et al., 2001).

\subsection{Experimental animals and infection}

Thirty-two male and female 3 months old mongrel dogs from the kennel of the Federal University of Ouro Preto, MG, Brazil were fed a commercial ration, and water was available ad libitum. Before the study, the animals were treated with anti-helminthes and immunized against infectious diseases. For the acute model, the animals were inoculated with 2000 blood trypomastigotes per $\mathrm{kg}$ of bodyweight via peritoneal, of $T$. cruzi Berenice-78 (10 dogs), Y (6 dogs) and Colombian (6 dogs) strains. For the chronic model, 10 animals were inoculated with Berenice-78 strain. Two untreated dogs were used as the positive control group.

\subsection{Treatment schedule}

The treatment schedule was $7 \mathrm{mg}$ of $\mathrm{Bz}$ per $\mathrm{kg}$ bodyweight administered orally in two doses daily for 45 days. In the acute model, the animals were treated 12-22 days after $T$. cruzi detection, while in the chronic model they were treated 100 days after inoculation. The animals were considered cured when parasitologic (fresh blood examination, hemoculture), molecular (polymerase chain reaction, PCR) and serological methods (enzymelinked immunosorbent assay, ELISA and complement mediated lysis, CoML) were all negative. 


\subsection{Parameters evaluated}

\subsubsection{Parasitaemia and mortality}

The parasitaemia of the animals was examined from the 10th day of infection until the parasites could no longer be detected by collecting fresh blood from the marginal ear vein. Mortality rate was expressed as a cumulative percentage of animals that died.

\subsubsection{Hemoculture}

The hemoculture technique (Chiari et al., 1989) was performed before treatment, and at 1 and 6 months post-treatment for acute and chronic models. Hemocultures were examined monthly up to 120 days for detecting $T$. cruzi parasites.

\subsubsection{Polymerase chain reaction assay}

Ten milliliters of blood were collected from acute and chronic animals 1 and 6 months posttreatment. The samples were immediately mixed with an equal volume of $6 \mathrm{M}$ guanidine $\mathrm{HCl} / 0.2 \mathrm{M}$ EDTA solution (Ávila et al., 1991), maintained at room temperature for 1 week and boiled for 15 min to break the minicircles (Britto et al., 1993). Three DNA extractions were performed according to Wincker et al. (1994), but using $40 \mu \mathrm{g}$ of Glycogen (Boehringer Mannheim) to precipitate the DNA. PCR conditions were the same described by Gomes et al. (1998), but 20 pmol of S35 (5'-AAATAATGTACGGG(T/G)GAGATGCATGA-3') and S36 (5'-GGGTTCGATTGGGGTTGGTGT-3') primers were used (Ávila et al., 1990). Briefly, $2 \mu 1$ of blood DNA template was added to $10 \mathrm{mM}$ Tris $-\mathrm{HCl}$ (pH 9.0), $75 \mathrm{mM} \mathrm{KCl}$, $3.5 \mathrm{mM} \mathrm{MgCl}, 0.1 \%$ Triton X-100, $0.2 \mathrm{mM}$ of each dATP, dCTP, dGTP and dTTP (Sigma Chemical Co.), 1.0 unit of Taq DNA polimerase (Promega), and water in a $20 \mu \mathrm{l}$ reaction volume. The reaction mixtures were overlaid with $30 \mu 1$ of mineral oil and subjected to 35 cycles of amplification in a Research Programmable Thermal Controller (MiniCycler TM). The temperature profile was $95{ }^{\circ} \mathrm{C}$ for $5 \mathrm{~min}$ for denaturation, two cycles with annealing at $30{ }^{\circ} \mathrm{C}$ for $2 \mathrm{~min}$, followed by 33 cycles with the annealing temperature increased to $40{ }^{\circ} \mathrm{C}$ and a final extension at $72{ }^{\circ} \mathrm{C}$ for $5 \mathrm{~min}$. Five microliters of PCR products were analyzed by electrophoresis on a $6 \%$ polyacrylamide gel and visualized by silver staining (Santos et al., 1993).

\subsubsection{Serological profile}

Serum samples were collected from the blood of acute infected dogs before and monthly after the inoculation for 6 months and of those chronically infected up to 3 years post-treatment. The serum samples were stored at $-20{ }^{\circ} \mathrm{C}$ and ELISA tests were performed according to Voller et al. (1976). T. cruzi Y strain obtained from acellular culture in LIT medium (ELISA-epimastigote) and from VERO cellular culture (ELISA-trypomastigote) were used as antigens. The sera were tested in parallel using both antigens and peroxidase conjugated goat anti-dog IgG (Sigma Chemical Co.). The cut-off was determined using the absorbance mean of 10 uninfected animals plus two standard deviations.

\subsubsection{Complement mediated lysis}

The CoML assay with $T$. cruzi $\mathrm{Y}$ strain trypomastigotes from tissue culture were performed before and 6 months post-treatment in the acute model, and for the chronic model before, 9 and 24 months post-treatment. This test was performed as described by Krettli et al. (1979) and modified by Galvão et al. (1993). Briefly, trypomastigotes forms from VERO cellular culture were concentrated to $6 \times 10^{6}$ parasites $/ \mathrm{ml}$. An aliquot of $50 \mu \mathrm{l}$ of a suspension of these trypomastigotes plus $50 \mu$ of the test serum (1:2 and 1:4 dilutions) were incubated at $37{ }^{\circ} \mathrm{C}$ for $30 \mathrm{~min}$ and then placed on ice. Fresh human serum from healthy volunteers was added as a source of complement and the number of living trypomastigotes was counted on a hemocytometer. Tubes were then reincubated in the same conditions for $45 \mathrm{~min}$ to determine the percentage lysis. Samples were examined at microscopy, and the number of motile intact trypomastigotes were counted again and compared to the number of lysed parasites. This assay was considered positive when lysis was greater than $20 \%$. Sera used as negative control for the serological tests were also used as control for the CoML reaction. 


\section{Results}

\subsection{Side-effects and toxicity}

$\mathrm{Bz}$ was well tolerated by the dogs and no side effects were observed during the study.

\subsubsection{Acute model}

The parasitaemia was suppressed from the first to the third day post-treatment in all treated animals. However, three (18.75\%) and five $(31.25 \%)$ out of 16 treated animals showed positive hemoculture and PCR results, respectively, in at least one test (Table 1). All untreated control animals were positive for hemoculture and PCR.

High levels of $T$. cruzi specific IgG antibodies were detected around 20 days after inoculation in sera of the untreated control group (Fig. 1A and B). Among treated animals, the antibody levels were below of the cut-off limits 20 weeks posttreatment in 11 animals, seven of them infected with Berenice-78 and four with Y strains (ELISAepimastigote). Five animals showed antibody levels similar to untreated controls, one infected with Berenice-78 and four with Colombian strain (Fig. 1A). ELISA-trypomastigotes assays showed antibody levels higher than the cut-off limits in all treated animals (Fig. 1B).

Lytic antibodies were detected in sera of $75 \%$ of infected dogs between the 12th and the 21st day (Fig. 2A) and remained positive in the control group. Among the treated animals, the CoML was persistently positive 6 months post-treatment in five dogs, one of them infected with Berenice-78 and four with the Colombian strain (Fig. 2A). All animals that had negative parasitologic, PCR and ELISA-epimastigote tests also had negative CoML 6 months post-treatment (Fig. 2A).

Based on hemoculture, PCR and serologic (ELISA-epimastigote and CoML) tests, 68.75\% $(11 / 16)$ of the treated animals were considered cured.

\subsection{Chronic model}

Parasitologic, molecular (Table 2 and Fig. 3) and serologic (Fig. 2B, Fig. 4A and B) tests were positive in all infected animals with Berenice-78 strain before treatment. On the other hand, at least one test of hemoculture and PCR remained positive in $12.5 \%$ and $62.5 \%$ of the animals, respectively, post-treatment. Both tests were positive in the untreated animals (Table 2 and Fig. 3).

The serologic pattern was clearly different between treated and controls animals in ELISAepimastigote test (Fig. 4A). Based on parasitologic and PCR evaluations, the animals were divided into three groups: (1) untreated controls; (2) treated with positive parasitologic and PCR tests and (3) treated with negative parasitologic and PCR tests. A slow decrease of absorbance levels was observed in the group 1 during the experimental period (Fig. 4A). On the other hand, groups 2 and 3 showed an abrupt decreasing in the absorbance levels after beginning the $\mathrm{Bz}$ treatment. However, the absorbance levels of the group 2 were always slightly higher than group 3 (Fig. 4A), while three animals of the group 3 showed a negative sero-conversion at the $37 \mathrm{th}$, 72 nd and 113th weeks post-treatment. The treatment did not induce changes in serologic patterns, which were similar to the control group when ELISA-trypomastigote testing was used (Fig. 4B).

Lytic antibodies persisted in higher levels for 9 months after treatment, even in sera of animals that had negative parasitologic, PCR and ELISAepimastigote tests (Fig. 2B). Three animals with negative parasitologic, PCR and ELISA-epimastigote tests switched from CoML positive to negative 24 months post-treatment. In the untreated control and treated animals with positive parasitologic, PCR and serologic tests, the CoML was persistently positive (Fig. 2B).

On the face of parasitologic, PCR and serologic results, $37.5 \%(3 / 8)$ of treated animals were considered cured.

\section{Discussion}

A major goal on Chagas' disease research is the development from specific drug to eliminate $T$. cruzi from acutely or chronically infected individuals. Moreover, the establishment of routine methods to discriminate among infected and cured patients and the implementation of studies to 

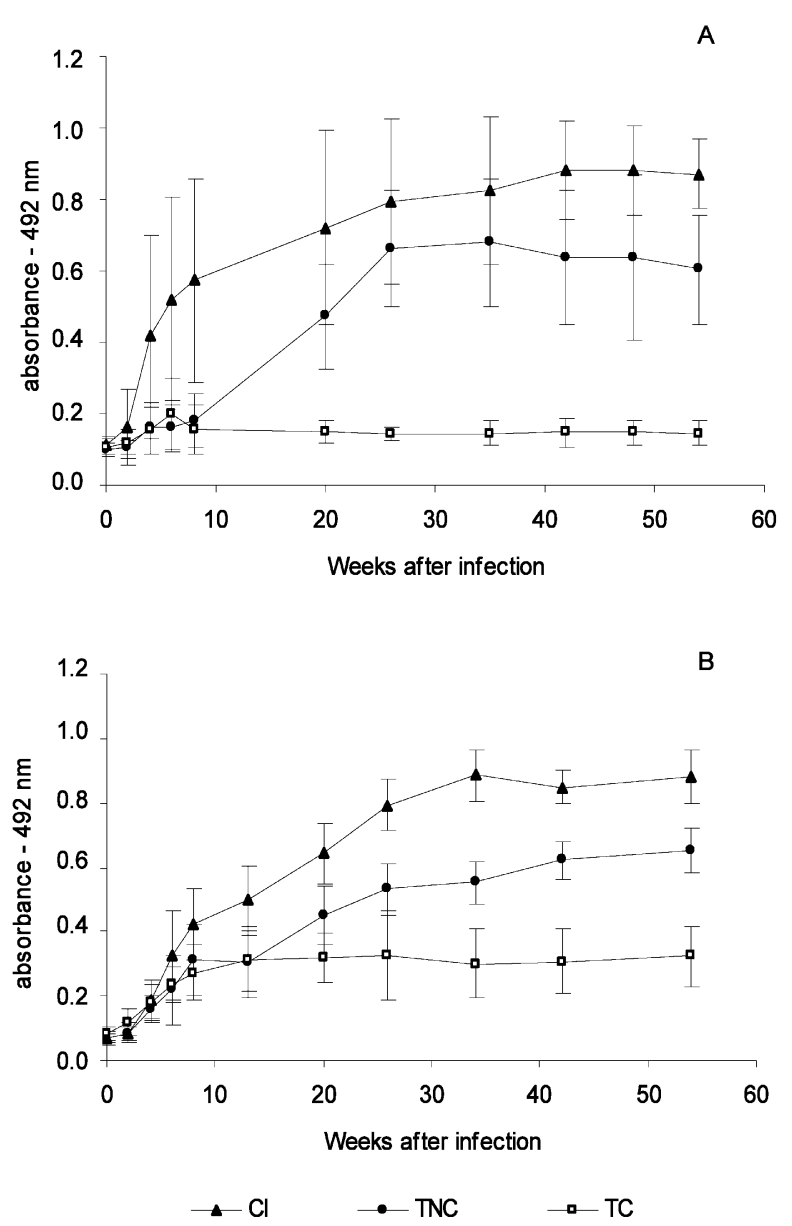

Fig. 1. T. cruzi specific IgG antibodies in sera of infected control group (CI) and dogs treated in the acute phase of the infection with $7 \mathrm{mg}$ of benznidazole per $\mathrm{kg}$ bodyweight, divided in two daily doses, for 45 days. TC cured and TNC noncured animals ((A) ELISA-epimastigote; (B) ELISA-trypomastigote).

establish experimental models to evaluate potential therapeutic agents for the control of this disease are important. In this work, we reported the relative therapeutic efficacy of $\mathrm{Bz}$ against $T$. cruzi in a canine model for acute and chronic phases of the disease.

Parasitological and serological tests were negative in 67.5 and $37.5 \%$ of treated animals during the acute and recent chronic phases, respectively. Most clinical trials have reported cure rates of 60 $70 \%$ for the acute phase of the infection (Andrade et al., 1992; Galvão et al., 1993; Bahia-Oliveira et
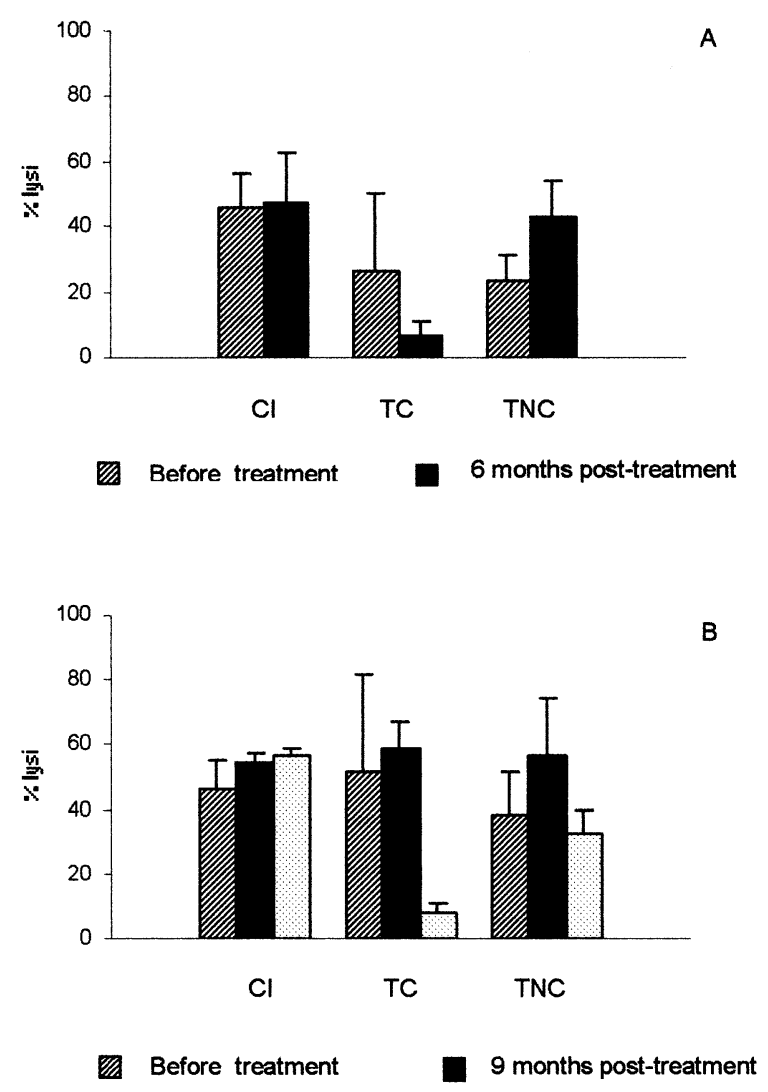

\section{4 months post-treatment}

Fig. 2. Percentage of lytic antibodies in sera of the infected control group (CI), treated and cured (TC) and treated uncured animals (TNC). (A) Animals treated in the acute phase and (B) animals treated in chronic phase of the disease. All animals were treated with $7 \mathrm{mg}$ of benznidazole per $\mathrm{kg}$ bodyweight, divided in two daily doses, for 45 days.

al., 2000). Cure rates of only $10-17 \%$ have been reported for patients in the chronic phases of Chagas' disease (Ferreira, 1990; Galvão et al., 1993; Braga et al., 2000). However, recent publications have described an efficacy from 55.8 to $62 \%$ in children who received $\mathrm{Bz}$ treatment (Andrade et al., 1996; Sosa Estani et al., 1998). Similarly, the time of infection could be a decisive factor in the therapeutic success, since in humans or in our model, the cure index was higher than those obtained in adult patients (Cançado, 1999). Another factor that may interfere with the therapeutic effectiveness is the time of drug administration because in clinical trials, where the 
Table 1

Parasitologic and molecular tests in blood of infected dogs with T. cruzi Berenice-78, Y and Colombian strains and treated in acute phase with $7 \mathrm{mg}$ of benznidazol for 45 days

\begin{tabular}{|c|c|c|c|c|c|c|}
\hline \multirow{3}{*}{$\begin{array}{l}\text { Groups } \\
\text { Treated }\end{array}$} & \multirow{3}{*}{$\begin{array}{l}\text { Survived animals/total } \\
\text { of animals }\end{array}$} & \multirow{2}{*}{\multicolumn{2}{|c|}{$\frac{\text { Positive Hc/No. tested }}{\text { Months after treatment }}$}} & \multicolumn{2}{|c|}{ Positive PCR/No. tested } & \multirow{3}{*}{$\begin{array}{l}\text { Positive parasitological } \\
\text { tests/total of animals }\end{array}$} \\
\hline & & & & & & \\
\hline & & 1 st & 6 th & $1 \mathrm{st}$ & 6 th & \\
\hline \multicolumn{7}{|l|}{ Treated } \\
\hline Berenice-78 & $8 / 8$ & $1 / 8$ & $0 / 8$ & $1 / 8$ & $1 / 8$ & $1 / 8(12.5 \%)$ \\
\hline Colombian & $4 / 4$ & $1 / 4$ & $1 / 4$ & $4 / 4$ & $4 / 4$ & $4 / 4(100 \%)$ \\
\hline Y & $4 / 4$ & $0 / 4$ & $0 / 4$ & $0 / 4$ & $0 / 4$ & $0 / 4(0 \%)$ \\
\hline Untreated & $4 / 6$ & $2 / 4$ & $3 / 4$ & $4 / 4$ & $4 / 4$ & $4 / 4(100 \%)$ \\
\hline
\end{tabular}

No., Number; Hc, Hemoculture.

Table 2

Parasitologic and molecular tests in blood of infected dogs with T. cruzi Berenice-78 strain and treated in chronic phase with $7 \mathrm{mg}$ of benznidazole for 45 days

\begin{tabular}{|c|c|c|c|c|c|c|c|c|}
\hline \multirow[t]{3}{*}{ Groups } & \multirow{3}{*}{$\begin{array}{l}\text { Survived animals/ } \\
\text { total animals }\end{array}$} & \multirow{2}{*}{\multicolumn{3}{|c|}{$\frac{\text { Positive Hc/No. tested }}{\text { Months after treatment }}$}} & \multicolumn{3}{|c|}{ Positive PCR/No. tested } & \multirow{3}{*}{$\begin{array}{l}\text { Positive tests post-treatment/ } \\
\text { total animals }\end{array}$} \\
\hline & & & & & & & & \\
\hline & & Before & $1 \mathrm{st}$ & 6 th & Before & $1 \mathrm{st}$ & 6 th & \\
\hline Treated & $8 / 8$ & $6 / 8$ & $0 / 8$ & $1 / 8$ & $8 / 8$ & $5 / 8$ & $5 / 8$ & $5 / 8(62.5 \%)$ \\
\hline Untreated & $2 / 2$ & $2 / 2$ & $1 / 2$ & $1 / 2$ & $2 / 2$ & $2 / 2$ & $2 / 2$ & $2 / 2(100 \%)$ \\
\hline
\end{tabular}

No., Number; Hc, Hemoculture.

treatment was administered for 30 days in chronic chagasic patients, the cure rate was $0-3 \%$ (Braga et al., 2000; Fabbro de Suasnábar et al., 2000). Therefore, the cure rate $(37.5 \%)$ of the treated animals in recent chronic phase could be related to the time of treatment (45 days).

The cure indexes of infected animals with $T$. cruzi Berenice-78 and Colombian strains were similar those obtained with the murine model
(Veloso et al., 2001; Filardi and Brener, 1987). On the other hand, all of the dogs infected with $T$. cruzi $\mathrm{Y}$ strain and treated in the acute phase were cured. This is interesting because this strain was partially resistant to $\mathrm{Bz}$, in experimentally infected mice that showed a cure rate of $47 \%$ (Filardi and Brener, 1987). The susceptibility to Bz and Nifurtimox compounds can be related to genetics characteristics of $T$. cruzi populations (Revollo et

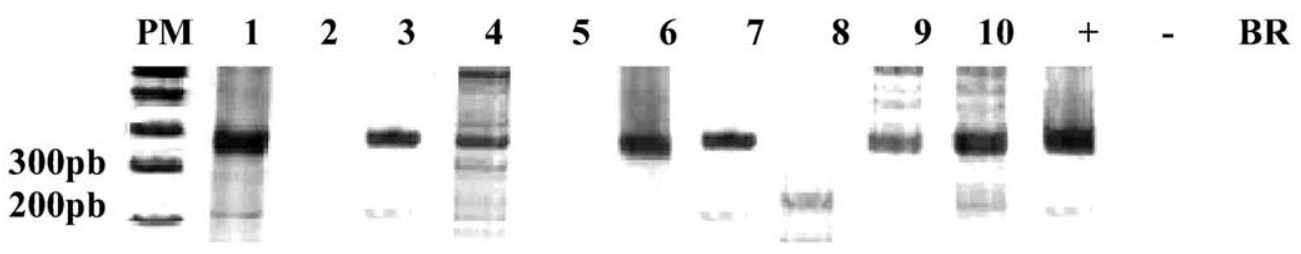

Fig. 3. Amplified PCR products $\approx 330$ base pairs (bp) on $6 \%$ polyacrilamide gel, silver stained. MW, molecular weight 100 bp ladder; lanes 2, 5 and 8 treated and cured; lanes 1,3, 4, 6 and 7 treated and noncured, lanes 9 and 10 are infected controls; + , infected controls; - , uninfected controls, and BR is an internal control without DNA. 

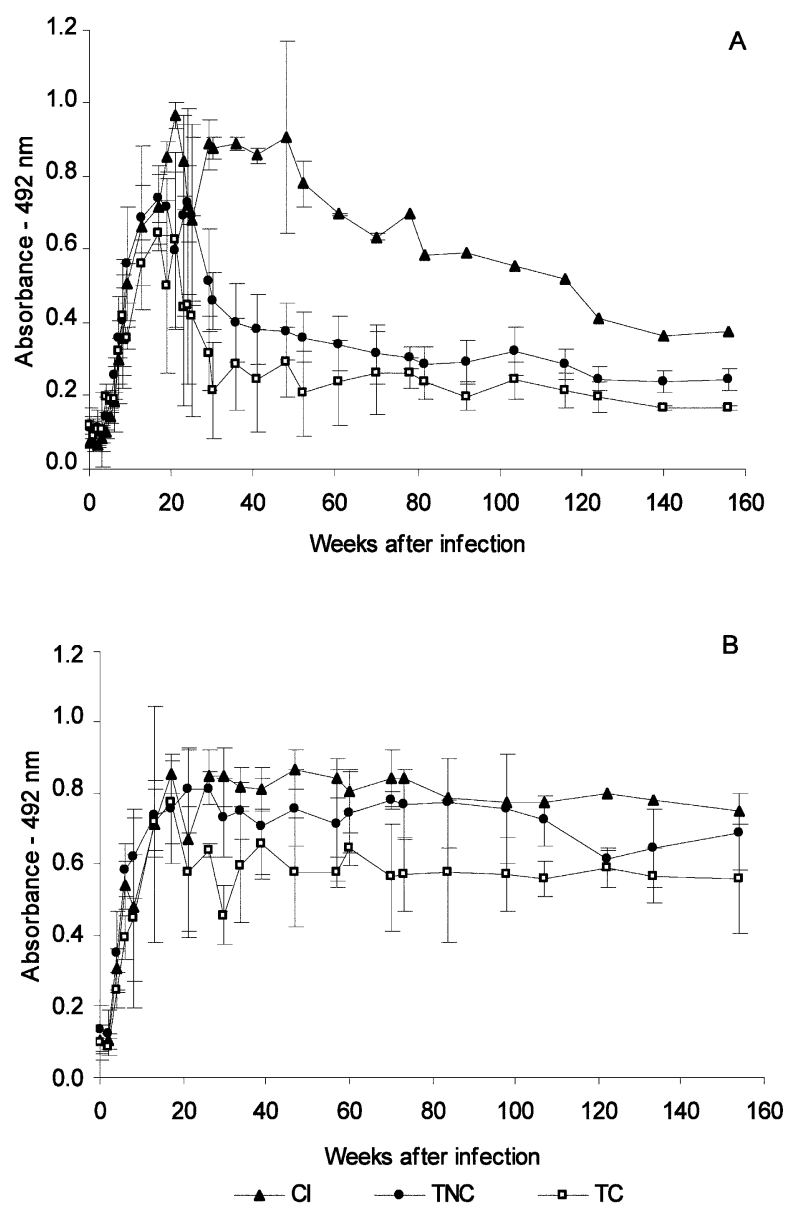

Fig. 4. T. cruzi specific $\operatorname{IgG}$ antibodies in sera of infected control group (CI) and treated dogs in the chronic phase of infection with $7 \mathrm{mg}$ of benznidazole per $\mathrm{kg}$ bodyweight for 45 days. (TC) treated cured and (TNC) treated noncured animals ((A) ELISA-epimastigote; (B) ELISA-trypomastigote).

al., 1998; Toledo et al., 2000). This data suggest that further studies to evaluate the immune responses induced by $T$. cruzi in different host species and its relationship with Chagas' disease chemotherapy are required.

A significant reduction in the number of positive hemocultures, which indicates a decrease or clearance of parasites, shows the specific antiparasitic activity to Bz. T. cruzi specific DNA sequences were detected, by PCR amplification, in all animals that were positive by conventional serology and CoML assays. The high sensitivity of PCR compared with xenodiagnosis and hemocul- ture has been used previously to measure the cure rate in treated chagasic patients (Britto et al., 1995; Silveira et al., 2000). This study reinforces the use of PCR as a useful tool for monitoring parasite cure of chagasic patients submitted to a specific chemotherapy.

Treated and cured animals in the acute phase of the chagasic infection had a negative ELISAepimastigote serum conversion in the first month post-treatment. These findings are similar to those observed in treated patients that had negative conventional serology about 12 months posttreatment (Cançado, 1999). However, different serological profiles in ELISA related to trypomastigotes or epimastigotes antigens were observed, and these differences were striking in chronically treated animals. Similar differences have been observed in treated chagasic patients in both, acute and chronic phases, when epimastigotes or trypomastigotes were used as antigens in ELISA, indirect immunofluorescence and Western blot (Umezawa et al., 1999).

For the diagnosis of Chagas' disease, epimastigotes antigens present as inconvenient the low specificity due to cross-reactions. Recently, the high sensitivity and low specificity of epimastigotes antigens, when compared with recombinant antigens, have been reported (Umezawa et al., 1999). Therefore, post-treatment evaluation with epimastigotes appeared to be more effective than the trypomastigotes antigens.

Cure assessment in chronic chagasic infection is still controversial due to the lack of sensitive and reliable criteria, and because of the persistence of anti-T. cruzi antibodies post-treatment. In chronic chagasic patients treated with trypanocidal drugs, a decrease in specific antibodies has been observed and could be used as an indicator of being cure (Luquetti and Rassi, 1999). In chronic treated animals model that did not show negative seroconversion, significant reduction in antibody levels compared with baseline values and control untreated animals were observed. Other authors have observed a decrease in specific antibody levels in children previously treated with trypanocidal drugs without negative seroconversion (Andrade et al., 1996; Sosa Estani et al., 1998; Fabbro de Suasnábar et al., 2000). However, antibody levels 
were not substantially changed by therapeutic activity when ELISA-trypomastigote were used, thus showing the importance of full knowledge of antibodies profiles obtained from each antigen during chagasic infection and after a specific treatment. Therefore, experimental models may be important for the evaluation of new candidate antigens.

The negative seroconversion of CoML was observed between the 6th and 24th months after treatment in $76 \%$ of treated and cured chronic chagasic patients (Galvão et al., 1993). These results were similar to those reported in our study where negative seroconversion was observed in the acute model 6 months post-treatment, and between the 9th and the 24th month for the chronic model.

In conclusion, the proposed experimental model can be of great importance for further studies on chemotherapy of Chagas' disease, which includes the evaluation of new candidate compounds. The establishment of the specific therapeutic effects on the immune state and the evolution of Chagas' disease, could initiate the development of new methods (such as PCR) or criteria for evaluating the cure of parasitosis.

\section{Acknowledgements}

This work was supported by grants from the Fundação de Amparo à Pesquisa do Estado de Minas Gerais (FAPEMIG), Universidade Federal de Ouro Preto (UFOP) and Coordenação de Aperfeiçoamento de Pessoal do Ensino Superior (CAPES). We also thank Dr Luiz Carlos Crocco Afonso and Dr Cláudia de Mattos Bellato for his language revision assistance.

\section{References}

Andrade, A.L.S.S., Zicker, F., Oliveira, M.R., Silva, A.S., Luquetti, A., Travassos, L.R., Almeida, S.S., Andrade, J.C., Martelli, C.M., 1996. Randomised trial of efficacy of benznidazole in treatment of early Trypanosoma cruzi infection. The Lancet 348, 1407-1413.

Andrade, S.G., Magalhães, J.B., Pontes, A.L., 1985. Evaluation of chemotherapy with benznidazole and nifurtimox in mice infected with Trypanosoma cruzi of different types. Bull. WHO 63, 721-726.

Andrade, S.G., Stocker-Guerret, S., Pimentel, A.S., Grimaud, J.A., 1991. Reversibility of cardiac fibrosis in mice chronically infected with Trypanosoma cruzi, under specific chemotherapy. Mem. Inst. Oswaldo Cruz 86, 187-200.

Andrade, S.G., Rassi, A., Magalhães, J.B., Filho, F.F., Luquetti, A.O., 1992. Specific chemotherapy of Chagas' disease: a comparison between the response in patients and experimental animals inoculated with the same strain. Trans. R. Soc. Trop. Med. Hyg. 86, 624-626.

Andrade, Z.A., Andrade, S.G., 1980. A patologia da doença de Chagas experimental no cão. Mem. Inst. Oswaldo Cruz 75, 77-95.

Andrade, Z.A., 1984. The canine model of Chagas' disease. Mem. Inst. Oswaldo Cruz 79, 77-83.

Ávila, H.A., Sigman, D.S., Cohen, L.M., Millikan, R.C., Simpson, L., 1991. Polymerase chain reaction amplification of Trypanosoma cruzi kinetoplast minicircle DNA isolation from whole blood lysates: diagnosis of chronic Chagas' disease. Mol. Biochem. Parasitol. 40, 211-222.

Ávila, H.A., Gonçalves, A.M., Nehme, N.C., Morel, C.M., Simpson, L., 1990. Schizodeme analysis of Trypanosoma cruzi stocks from South and Central America by analysis of PCR-amplified minicircle variable region sequences. Mol. Biochem. Parasitol. 42, 175-187.

Bahia-Oliveira, L.M.G., Gomes, J.A.S., Cançado, J.R., Ferrari, T.C., Lemos, E.M., Luz, Z.M.P., Moreira, M.C., Gazzinelli, G., Corrêa-Oliveira, R., 2000. Immunological and clinical evaluation of chagasic patients subjected to chemotherapy during the acute phase of Trypanosoma cruzi infection 1430 years ago. J. Infect. Dis. 182, 634-638.

Braga, M.S., Lauria-Pires, L., Argañaraz, E.R., Nascimento, R.J., Teixeira, A.R.L., 2000. Persistent infections in chronic Chagas' disease patients treated with anti-Trypanosoma cruzi nitroderivatives. Rev. Inst. Med. Trop. São Paulo 42, 157-161.

Britto, C., Cardoso, M.A., Wincker, P., Morel, C.M.A., 1993. Simple protocol for cleavage of Trypanosoma cruzi kinetoplast DNA present in blood samples and its use in polymerase chain reaction (PCR) based diagnosis of chronic Chagas' disease. Mem. Inst. Oswaldo Cruz 88, 171-172.

Britto, C., Cardoso, M.A., Monteiro-Vanni, C.M., HasslocherMoreno, A., Xavier, S.S., Oelemann, W., Santoro, A., Pirmez, C., Wincker, P., 1995. Polymerase chain reaction detection of Trypanosoma cruzi in human blood samples as a tool for diagnosis and treatment evaluation. Parasitology $110,241-247$.

Cançado, J.R., 1999. Evolution of knowledge on the etiological diagnosis of chagasic infection. Mem. Inst. Oswaldo Cruz 94, 283-284.

Chiari, E., Dias, J.C.P., Lana, M., Chiari, C.A., 1989. Hemocultures for the parasitological diagnosis of human chronic Chagas' disease. Rev. Soc. Bras. Med. Trop. 22, 19-23.

Fabbro de Suasnábar, D., Arias, E., Streiger, M., Piacenza, M., Ingaramo, M., Del Barco, M., Amicone, N., 2000. Evolutive 
behavior towards cardiomyopathy of treated (nifurtimox or benznidazole) and untreated chronic chagasic patients. Rev. Inst. Med. Trop. São Paulo 42, 99-109.

Federici, E.E., Abelmann, W.H., Neva, F.A., 1964. Chronic and progressive myocarditis and myositis in $\mathrm{C}_{3} \mathrm{H}$ mice infected with Trypanosoma cruzi. J. Trop. Med. Hyg. 13, $272-280$.

Ferreira, H.O., 1990. Tratamento da forma indeterminada da doença de Chagas com nifurtimox e benznidazol. Rev. Soc. Bras. Med. Trop. 23, 209-211.

Filardi, L.S., Brener, Z., 1987. Susceptibility and natural resistance of Trypanosoma cruzi strains to drugs used clinically in Chagas' disease. Trans. R. Soc. Med. Hyg. 81, $755-759$.

Galvão, L.M.C., Nunes, R.M.B., Cançado, J.R., Brener, Z., Krettli, A.U., 1993. Lytic antibody titre as a means of assessing cure after treatment of Chagas' disease. Trans. R. Trop. Med. Hyg. 87, 220-223.

Gomes, M.L., Macedo, A.M., Vago, A.R., Pena, S.D.J., Galvão, L.M.C., Chiari, E., 1998. Trypanosoma cruzi: Optimization of polymerase chain reaction for detection in human blood. Exp. Parasitol. 88, 28-33.

Krettli, A.U., Weisz-Carrington, P., Nussenzweig, R.S., 1979. Membrane-bound antibodies to bloodstream Trypanosoma cruzi in mice, strain differences in susceptibility to complement-mediated lysis. Clin. Exp. Immunol. 37, 416-423.

Krettli, A.U., Cançado, J.R., Brener, Z., 1984. Criterion of cure of human Chagas' disease after specific chemotherapy: recent advances. Mem. Inst. Oswaldo Cruz 79, 157-164.

Lana, M., Chiari, C.A., 1986. Caracterização biológica comparativa das cepas Berenice-62 e Berenice-78 de Trypanosoma cruzi, isoladas da mesma paciente em diferentes períodos. Mem. Inst. Oswaldo Cruz 81, 247-253.

Lana, M., Chiari, E., Tafuri, W.L., 1992. Experimental Chagas' disease in dogs. Mem. Inst. Oswaldo Cruz 87, 59-71.

Luquetti, A.O., Rassi, A., 1999. Testes sorológicos e controle pós-terapêutico. Rev. Soc. Bras. Med. Trop. 32, 86.

Revollo, S., Oury, B., Laurent, J.P., Barnabé, C., Quesney, V., Carriére, V., Noel, S., Tibayrenc, M., 1998. Trypanosoma cruzi: impact of clonal evolution of the parasite on its biological and medical properties. Exp. Parasitol. 89, 3039.

Santos, F.R., Pena, S.D.J., Epplen, J.T., 1993. Genetic and population study of a Y-linked tetranucleotide repeat DNA polymorphism with a simple non-isotopic technique. Hum. Genet. 90, 655-656.

Shikanai-Yasuda, M.A., Lopes, M.H., Tolezano, J.E., Umezawa, E., Amato Neto, V., Barret, A.C., Higaki, Y.,
Moreira, A.A., Funayania, G., Barone, A.A., 1990. Acute Chagas' disease: transmission routes, clinical aspects and response to specific therapy in diagnosed cases in an urban center. Rev. Inst. Med. Trop. São Paulo 32, 16-27.

Silva, L.H.P., Nussenzweig, V., 1953. Sobre uma cepa de Trypanosoma cruzi altamente virulenta para o camundongo branco. Folia Clin. Biol. 20, 191-203.

Silveira, C.A.N., Castilho, E., Castro, C., 2000. Avaliação do tratamento específico para o Trypanosoma cruzi em crianças, na evolução da fase indeterminada. Rev. Soc. Bras. Med. Trop. São Paulo 33, 191-196.

Sosa Estani, S., Segura, E.L., Ruiz, A.M., Velazquez, E., Porcel, B.M., Yampotis, C., 1998. Efficacy of chemotherapy with benznidazole in children in the indeterminate phase of Chagas' disease. Am. J. Trop. Med. Hyg. 59, 526-529.

Toledo, M.J.O., Guilherme, A.L.F., Silva, J.C., Gasperi, M.V., Mendes, A.P., Gomes, M.L., Araújo, S.M., 1997. Trypanosoma cruzi: chemotherapy with benznidazole in mice inoculated with strains from Paraná state and from different endemic areas of Brazil. Rev. Inst. Med. Trop. São Paulo 39, 283-290.

Toledo, M.J.O., Lana, M., Bahia, M.T., Carneiro, C.M., Alves, C.F., Martins, H.R., Tibayrenc, M., Tafuri, W.L., 2000. Evaluation of chemotherapy with benznidazole and itraconazole in mice infected with different Trypanosoma cruzi clonal genotypes. Mem. Inst. Oswaldo Cruz 95, 314.

Umezawa, E.U., Levy, A.M.A., Galvão, L.M.C., Gomes, L.M., Shikanai-Yasuda, M.A., Luquetti, A.O., 1999. O Papel da sorohogia em pacientes chagásicos submetidos à quimioterapia anti-Trypanosoma cruzi. Rev. Soc. Bras. Med. Trop. 32,80

Veloso, V.M., Carneiro, C.M., Toledo, M.J.O., Lana, M., Chiari, E., Tafuri, W.L., Bahia, M.T., 2001. Variation in susceptibility to benznidazole in isolates derived from Trypanosoma cruzi parental strains. Mem. Inst. Oswaldo Cruz 96, 1005-1011.

Viotti, R., Vigliano, C., Armenti, H., Segura, E., 1994. Treatment of chronic Chagas' disease with long-term follow-up. Am. Heart J. 127, 151-162.

Voller, A., Bidwell, D.E., Bartlett, A., 1976. Enzyme immunoassays in diagnostic medicine. Theory and practice. Bull. WHO 53, 55-65.

Wincker, P., Britto, C., Pereira, J.B., Cardoso, M.A., Oelemann, W., Morel, C.M., 1994. Use of a simplified polymerase chain reaction procedure to detect Trypanosoma cruzi in blood samples from chronic chagasic patients in a rural endemic area. Am. J. Trop. Med. Hyg. 51, 771-777. 